\title{
Effect of Spraying Organic Fertilizer and Grapes Fruiting Eyes Number on some of the Characteristics of Growth and Yield of the Local Cultivar, White Intensity, Yitis vinifera $\mathrm{L}$. Farhan, M. A. ${ }^{1}$, A. T. Salman ${ }^{2}$ and Ghadah A. Abdulwahab ${ }^{3}$ \\ ${ }^{1}$ Univ. of Anbar College of Agric. \\ ${ }^{2}$ Iraqi Ministry of Defense \\ "alaa_falluja@yahoo.com
}

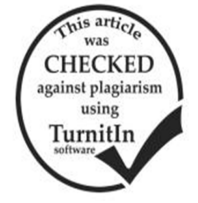

\begin{abstract}
This study has been carried out in Iraq, in Erbil province, for the season 2015/2016 to study the effect of spraying organic fertilizer and the number of eyes on the fruiting canes of the local cultivar (white intensity, vitis vinifera) on the characteristics of the vegetative growth and the yield. The results exceed the treatment of spraying organic fertilizer $\left(\mathrm{B}_{2}\right)$ for the characteristics of the vegetative growth length, the leaves' number, the leaf area, the number and the length of the grapes clusters and the grape berries quantity giving $78.87 \mathrm{~cm}, 24.73$ leaves, $130.41 \mathrm{~cm}^{2}, 4.00$ clusters, $21.72 \mathrm{~cm}$ and 85.33 grape berries.cluster ${ }^{-1}$, respectively. Concerning the number of the eyes, treatment $\left(\mathrm{T}^{3}\right)$ has preceded respecting the characteristics of the vegetative growth, the leaves' number, the clusters' number, the clusters' length and the grape berries' number which are $75.87 \mathrm{~cm} .22 .59$ leaves, $117.26 \mathrm{~cm}^{2}, 3.89$ clusters, $20.58 \mathrm{~cm}$ and 74.11 grape berries.cluster ${ }^{-1}$, respectively. For the treatments' interference, treatment $\left(\mathrm{B}_{2} \mathrm{~T}_{3}\right)$ recorded $87.07 \mathrm{~cm}, 29.80$ leaves, 146.67 $\mathrm{cm}^{2}, 4.67$ clusters, $24.73 \mathrm{~cm}, 104,33$ grape berries.clusters ${ }^{-1}$, respectively regarding the characteristics of the vegetative growth length, the leaves' number, the leaf area, the clusters' quantity, the clusters' length, the berries quantity.
\end{abstract}

Keywords: Grapes, pruning, fruiting eyes, organic fertilizer.

\section{INTRODUCTION}

The grapes belong to the species "Vitis", which pertain to the grapes' family "Vitaceae" (Hasan and Mohammed 1989). It has an economic, alimentary and health importance. Its economic importance is due to being used in many countries' economies. It can grow in lands which are not suitable for some fruit trees, such as sandy and low fertility soil (FAO, 2017). Its nutritional and health importance pertain to being used fresh or juicy; as well as its leaves are used in certain food industries, along with being used in many treatments for containing vitamins (A, B6, C, E) and minerals such as potassium, calcium and sodium (Hulme, 1971), which has a therapeutic importance for diseases such as osteoporosis, anemia and anti-cancer.

Although the chemical fertilizers are efficient in improving the plants' growth, it has been scientifically proved that these substances are dangerous for the environment and the human health. Therefore, the modern agricultural policy seeks to provide the nutrients which improve the plants growth, do not affect the environment and contribute to increase the tolerance of the plants concerning the inappropriate environmental conditions (Szabo and Hrotko, 2009). To achieve these goals, nutritive solutions for growth have been used in the last phase. These nutritive solutions may be amino acids, organic acids and plant hormones. They have proved their efficiency in improving the growth and the productivity of various horticultural plants (Al-Temimi, 2009; Lisiecka and others, 2011). The eyes are considered vitally important for containing the principles of growth and fruiting. The fruiting pruning is one of the most important processes to obtain a high annual production (Morris and Brady, 2004). It is usually done using one year old wood and depending on two years old wood. When the appropriate environmental conditions are available, it grows to form the fruiting vegetative branch. This process is affected by the number of the eyes in the canes, but their influence is different depending on the type of the breeding used for the grapevine. According to the aforementioned, this study has been developed to find out the effect of spraying organic fertilizer and the number of the eyes on the canes regarding some of the vegetative and fruiting growth characteristics for the local cultivar, the white intensity (Vitis vinifera), whose breeding is made according to the wire method.

\section{MATERIALS AND METHODS}

The study has been made in one of the private sectors' farms in Erbil in 2016 to study the effect of spraying organic fertilizer and the number of the fruiting eyes on the canes of one year old for grapevine, whose cultivar category is white intensity (vitis vinifera), which has been bred following the wire method. The study duration is two years. The first year is for the organic fertilizer "Botryfun" with the concentration of $(4,3,0) \mathrm{ml}^{-}$ ${ }^{1}$, given respectively the symbols $\left(\mathrm{B}_{2}, \mathrm{~B}_{1}, \mathrm{~B}_{0}\right)$. For the second, the number of the eyes which are left on the canes are $(6,5,4,2)$ eye/cane and given the following symbols $\left(\mathrm{T}_{4}, \mathrm{~T}_{3}, \mathrm{~T}_{2}, \mathrm{~T}_{1}\right)$ in triplicate on $28 / 01 / 2016$. The vegetable growth data has been collected from 01/05/2016 to $01 / 07 / 2016$. It was a practical experiment based on the designing of randomized complete blocks design (RCBD) (Al-Mohammedi and Moayed, 2000). The results were analyzed according to the genistat system. The means were tested according to the least significant difference (L.S.D.) at the probability level of $5 \%$.

\section{RESULTS AND DISCUSSION}

The results of Table (1) indicates that the organic fertilizer has a moral effect on the length of the vegetative growths while the treatment $\mathrm{B}_{2}$ exceeded significantly the other treatments and gave $78.87 \mathrm{~cm}^{2}$ while the compared treatment recorded the lowest length value of $64.35 \mathrm{~cm}^{2}$. The number of eyes has significantly effect on the vegetative growth length. $T_{3}$ recorded the maximum value of $75.87 \mathrm{~cm}^{2}$ while $\mathrm{T}_{0}$ recorded the lowest length value of $68.37 \mathrm{~cm}^{2}$. Regarding the interference of the study factors, treatment $\mathrm{B}_{2} \mathrm{~T}_{3}$ exceeded significantly all the treatments giving the highest length value of $87.07 \mathrm{~cm}^{2}$ while treatment $\mathrm{B}_{0} \mathrm{~T}_{0}$ recorded the lowest length value of 62.63 $\mathrm{cm}^{2}$. 
Table 1. Effect of spraying organic fertilizer and the number of the fruiting eyes of grapes on the vegetative growths

\begin{tabular}{lccccc}
\hline Treatments & $\mathbf{T}_{\mathbf{0}}$ & $\mathbf{T}_{\mathbf{1}}$ & $\mathbf{T}_{\mathbf{2}}$ & $\mathbf{T}_{\mathbf{3}}$ & Mean B \\
\hline $\mathrm{B}_{0}$ & 62.63 & 63.43 & 64.70 & 66.63 & 64.35 \\
$\mathrm{~B}_{1}$ & 67.50 & 68.17 & 70.40 & 72.40 & 69.62 \\
$\mathrm{~B}_{2}$ & 74.97 & 75.70 & 77.73 & 87.07 & 78.87 \\
Means T & 68.37 & 69.10 & 70.94 & 75.87 & \\
\hline \multirow{2}{*}{ LSD 5\% } & $\mathrm{B}$ & \multicolumn{2}{c}{$\mathrm{T}$} & \multicolumn{2}{c}{$\mathrm{BxT}$} \\
& 1.59 & \multicolumn{2}{c}{1.84} & \multicolumn{2}{c}{3.18} \\
\hline
\end{tabular}

The results of Table (2) show a significant exceeding of the organic fertilizer in the leaves' number. Treatment $\mathrm{B}_{2}$ exceeded significantly the other treatments giving 24.73 leaves while the compared treatment recorded the lowest value of 16.52 leaves. Regarding the eyes number, they have significant effect. $\mathrm{T}_{3}$ recorded the highest value of 22.59 leaves while $\mathrm{T}_{0}$ recorded the lowest value of 18.38 leaves. Respecting the interference of the study factors, treatment $\mathrm{B}_{2} \mathrm{~T}_{3}$ exceeded significantly all the treatments giving the highest value of 29.80 leaves while treatment $\mathrm{B}_{0} \mathrm{~T}_{0}$ recorded the lowest value of 15.70 leaves.

Table 2. Effect of spraying organic fertilizer and the number of the fruiting eyes of grapes on the leaves number

\begin{tabular}{lccccc}
\hline Treatments & $\mathbf{T}_{\mathbf{0}}$ & $\mathbf{T}_{\mathbf{1}}$ & $\mathbf{T}_{\mathbf{2}}$ & $\mathbf{T}_{\mathbf{3}}$ & Mean B \\
\hline $\mathrm{B}_{0}$ & 15.70 & 16.10 & 16.87 & 17.40 & 16.52 \\
$\mathrm{~B}_{1}$ & 17.97 & 18.57 & 18.83 & 20.57 & 18.98 \\
$\mathrm{~B}_{2}$ & 21.47 & 22.27 & 25.40 & 29.80 & 24.73 \\
Means T & 18.38 & 18.98 & 20.37 & 22.59 & \\
\hline \multirow{2}{*}{ LSD 5\% } & $\mathrm{B}$ & \multicolumn{2}{c}{$\mathrm{T}$} & \multicolumn{2}{c}{$\mathrm{BxT}$} \\
& 0.59 & \multicolumn{2}{c}{0.68} & \multicolumn{2}{c}{1.18} \\
\hline
\end{tabular}

The results of Table (3) show that the organic fertilizer has a significant effect on the leaf area. Treatment $\mathrm{B}_{2}$ exceeded significantly all the treatments reaching to $130.41 \mathrm{~cm}^{2}$ while $\mathrm{B}_{0}$ recorded the lowest value of 88.62 $\mathrm{cm}^{2}$. Regarding the eyes number, they have significant effect on the leaf area. $T_{3}$ recorded the highest value of $117.26 \mathrm{~cm}^{2}$ while $\mathrm{T}_{0}$ recorded the lowest value of 98.62 $\mathrm{cm}^{2}$. Respecting the interference of the study factors, treatment $\mathrm{B}_{2} \mathrm{~T}_{3}$ exceeded significantly all the treatments giving the highest value of $146.67 \mathrm{~cm}^{2}$ while the treatment $\mathrm{B}_{0} \mathrm{~T}_{0}$ recorded the lowest value of $82.80 \mathrm{~cm}^{2}$. The vegetative growth characteristics have increased in consistence with the increase of the organic fertilizer. Adding organic fertilizer increases the vegetative characteristics due to the increase of the enzymes' efficiency which help the decomposition of the complex compounds that leads to the release of elements and increases then its readiness, along with their effects in the growth values (Morgan, 2008; Holger and Bergstrom, 2008). The role of the organic fertilizer consists in containing a number of the major and the minor elements which satisfies the need of the vegetative total, which leads to the increase of the cells' division and to the cells' expansion. Consequently, this leads to the increase of the leaves' expansion and to improve the vegetative growth strength of the plants, so that the photosynthesis efficiency and the leaves' chlorophyll increase due to the leaves spraying (Singh, 2003). Finally, this leads to the increase of the vegetative branches, the leaves' chlorophyll and the leaf area (Table 1, 2 and 3). This pertains to the growth nature of this cultivar category in which the number of the eyes on the canes increases to contain about (4-8), called fruit spurs, as in the case of the head training and cordon breeding (Hasan and Mohammed, 1989). The vegetative growth of the grapevine is affected by the previous storage of the nutrients processed in grapes for the previous season, which depends on the number of leaves in the single cane during the summer growth season, when the storage of carbohydrates in canes increases. Sugar and starch are deemed main nutrients. They are stored in the grapevine and they move then to the canes. They are stored in the rest period in form of sugar, cellulose or pectin. The sugar can be transformed into proteins or fats, which are very important for the vital processes and to increase the resistance of the grape respect the low temperature in winter. This stored material is very important for the vital processes at the growth's beginning because the vegetative branches depend on them before the leaves' growth (Oslobeanu and others, 1980).

Table 3. The effect of spaying organic fertilizer and the number of the fruiting eyes of grapes on the leaf area

\begin{tabular}{|c|c|c|c|c|c|}
\hline Treatments & $T_{0}$ & $T_{1}$ & $T_{2}$ & $\mathbf{T}_{3}$ & Mean B \\
\hline$\overline{\mathrm{B}_{0}}$ & 82.80 & 86.63 & 91.07 & 94.00 & 88.62 \\
\hline $\mathrm{B}_{1}$ & 97.17 & 100.90 & 108.47 & 111.10 & 104.41 \\
\hline $\mathrm{B}_{2}$ & 115.90 & 123.03 & 136.03 & 146.67 & 130.41 \\
\hline Means T & 98.62 & 103.52 & 111.86 & 117.26 & \\
\hline \multirow[t]{2}{*}{ LSD 5\% } & B & \multirow{2}{*}{\multicolumn{2}{|c|}{$\begin{array}{c}\mathrm{T} \\
2.53\end{array}$}} & \multirow{2}{*}{\multicolumn{2}{|c|}{$\begin{array}{l}\text { BxT } \\
4.38 \\
\end{array}$}} \\
\hline & 2.19 & & & & \\
\hline
\end{tabular}

The results of Tables $(4,5,6)$ show that the organic fertilizer has a significant effect on the clusters' number and length and on the clusters' grapes berries number. Treatment $\left(\mathrm{B}_{2}\right)$ exceeded significantly giving the highest value of the number and the length of clusters and the number of the grapes berries, respectively, amounting to 4.00 clusters, $21.72 \mathrm{~cm}^{2}$ and 85.33 grape berries.cluster ${ }^{-1}$ compared to treatment $\mathrm{B}_{0}$, which recorded the lowest value of the number and the length of the clusters and the number of grape berries amounting to 2.50 clusters, $17.32 \mathrm{~cm}^{2}$ and 46,42 grape berries.cluster respectively. Regarding the eyes number, they have significant effect. $T_{3}$ recorded the highest value for the number and the length of clusters and for the grape berries number amounting to 3.89 clusters, $20.58 \mathrm{~cm}^{2}$ and 74.11 grape berries.cluster ${ }^{-1}$, respectively.

$\mathrm{T}_{0}$ recorded the lowest value of the number and the length of clusters. The grape berries number is 3.11 clusters, $18.32 \mathrm{~cm}^{2}$ and 56.33 grape berries.cluster ${ }^{-1}$. Respecting the interference of the organic fertilizer and the number of the left eyes, treatment $\mathrm{B}_{2} \mathrm{~T}_{3}$ exceeded significantly all the treatments giving the highest value of the number and the length of clusters and the number of the grape berries amounting to 4.67 clusters, $24.73 \mathrm{~cm}^{2}$ and 104.33 grape berries.cluster ${ }^{-1}$ while the treatment $B_{0} T_{0}$ recorded the lowest value of the number and the length of clusters and the grape berries amounting to 2.00 clusters, $16.93 \mathrm{~cm}^{2}$ and 41.67 grape.clusters ${ }^{-1}$. The increase of the length and the number of clusters and the grape berries' number is attributed to the role of the elements which the organic fertilizer contains. They play a role in increasing the leaf area which, in turn, leads to increase the photosynthesis and the formation of made material in 
leaves, to their consecutive moving to the fruits and, consequently, to their growth increase. Nitrogen, also, enters in the oxygen formation (IAA), which is necessary for the elongation and the size increase of the cell (Naji, 2001). The increase of the left eyes on the canes leads to the increase of the fruiting branches and, consequently, to the increase of the grape clusters (Kadhim, 2009 and AlIshaqi, 2012). The increase of the grape berries number in the grape cluster may be attributed to the increase of leaves number which leads to the increase of the photosynthesis efficiency and the increase of the made material (Kadhim, 2009).

Table 4. The effect of spaying organic fertilizer and the number of the fruiting eyes of grapes on the number of the grapes clusters

\begin{tabular}{lccccc}
\hline Treatments & $\mathbf{T}_{\mathbf{0}}$ & $\mathbf{T}_{\mathbf{1}}$ & $\mathbf{T}_{\mathbf{2}}$ & $\mathbf{T}_{\mathbf{3}}$ & Mean B \\
\hline $\mathrm{B}_{0}$ & 2.00 & 2.33 & 2.67 & 3.00 & 2.50 \\
$\mathrm{~B}_{1}$ & 3.33 & 3.33 & 3.67 & 4.00 & 3.58 \\
$\mathrm{~B}_{2}$ & 4.00 & 4.00 & 3.33 & 4.67 & 4.00 \\
Means T & 3.11 & 3.22 & 3.22 & 3.89 & \\
\hline \multirow{2}{*}{ LSD 5\% } & $\mathrm{B}$ & \multicolumn{2}{c}{$\mathrm{T}$} & \multicolumn{2}{c}{ BxT } \\
& 0.69 & 0.79 & \multicolumn{2}{c}{1.38} \\
\hline
\end{tabular}

Table 5. The effect of spaying organic fertilizer and the number of the fruiting eyes of grapes on the grapes clusters

\begin{tabular}{|c|c|c|c|c|c|}
\hline Treatments & $\mathbf{T}_{\mathbf{0}}$ & $T_{1}$ & $\mathbf{T}_{2}$ & $T_{3}$ & Mean B \\
\hline$\overline{\mathrm{B}_{0}}$ & 16.93 & 17.30 & 17.50 & 17.57 & 17.32 \\
\hline $\mathrm{B}_{1}$ & 18.07 & 18.47 & 18.73 & 19.43 & 18.67 \\
\hline $\mathrm{B}_{2}$ & 19.97 & 20.60 & 21.60 & 24.73 & 21.72 \\
\hline Means T & 18.32 & 18.79 & 19.28 & 20.58 & \\
\hline LSD 5\% & B & & & & XT \\
\hline
\end{tabular}

Table 6. The effect of spaying organic fertilizer and the number of the fruiting eyes of grapes on the grapes berries number

\begin{tabular}{lccccc}
\hline Treatments & $\mathbf{T}_{\mathbf{0}}$ & $\mathbf{T}_{\mathbf{1}}$ & $\mathbf{T}_{\mathbf{2}}$ & $\mathbf{T}_{\mathbf{3}}$ & Mean B \\
\hline $\mathrm{B}_{0}$ & 41.67 & 45.00 & 48.00 & 51.00 & 46.42 \\
$\mathrm{~B}_{1}$ & 54.33 & 58.67 & 65.00 & 67.00 & 61.25 \\
$\mathrm{~B}_{2}$ & 73.00 & 77.00 & 87.00 & 104.33 & 85.33 \\
Means T & 56.33 & 60.22 & 66.67 & 74.11 & \\
\hline \multirow{2}{*}{ LSD 5\% } & $\mathrm{B}$ & \multicolumn{2}{c}{$\mathrm{T}$} & \multicolumn{2}{c}{ BxT } \\
& 1.97 & 2.28 & \multicolumn{2}{c}{3.95} \\
\hline
\end{tabular}

\section{REFERENCES}

Al-Mohammadi, Fadel Musleh and Mu'ayyad Ahmad Younis (2000). Agricultural Experiments Design and Analysis, Ministry of Higher Education and Scientific Research. Baghdad University. Iraq. 444. FAO,(207).production Yearbook,vol.39.
Hassan, Jabbar Abbas and Muhammad Abbas Salman (1989) Production of grapes. Publications of the House of Wisdom, University of Baghdad. Iraq. 600 pages.

Holger. K. and L. Bergstrom.2008. Organic crop production ambition and limitation .Spri. Sci., Hiedelberg Germany.Pp. 244.

Hulme, A.C.(1971).The Biochemistry of Fruit and Products. N.Y. Academic Press.USA,pp788.

Ishaqi, Jassem Mohammed Khalaf (2012). Effect of pruning and spraying of the growth regulator (Atonic) in the amount of the yield of the grapes of the visit Vini fera $\mathrm{L}$ for the two types of blackness and white intensity. Tikrit University Journal of Agricultural Sciences. 12 (3): 136-139.

Kazem, Raja Abdel Hadi (2009). Effect of load intensity on the growth of the quantitative and qualitative qualities of two grape varieties. Journal of Iraqi Agricultural Sciences. 60 (4): 1-8.

Lisiecka „J.; M. knaflewski ;T.spizewski; B. Fraszczak; A. kaluzewicz and W.krzesinski.2011. The effect of animal protein hydrolysate on quantity and quality of strawberry daughter plants CV." E lsanta "Acta.

Morgan. L. .2008. Flavor improvement with hydroponics . The growing edge May/June.www.growing edge.com Research. 2(2), 167-172 .

Morris, J .R. and P.L. Brady.(2004).The muscadine experience :Adding value to enhance profits . Ark. Agr. Expt. Sta. Res. Rept.974.

Naji, Abdullah Ali Mohamed. Effect of some nutrients on the growth, concentration and concentration of certain nutrients and methoxsalen in fig trees Ficus carica L. Black Diyala. Master Thesis. faculty of Agriculture. Baghdad University. Iraq.

Oslobeanu, M. Oprean, M. Alexandrescu , I. Georgescu, M. Banits, P. Jianu, 6, (1980). Viticultura generala si speciala. Editura didactica si pedagogica, Bucuresti, R.S Romania, P 666.

Singh, A. 2003. Fruit Physiology and Production. 5th ed. Kalyani Publishers. New Delhi -110002.

Szabo.V. ;K.Hrotko .2009. Preliminary results of biostimulator treatments on Crategus and Prunusstockplants .Bull.UASVM Horticulture 66(1). 223-228.

Tamimi, Jamil Yassin Ali. Effect of hyomic acid and marine algae extracts on growth and chemical properties. Rosemarinusofficinalisl. The Sixth Scientific Conference of the Faculty of Education, University of Tikrit, Department of Life Sciences, Plant Research, pp. 1-17.

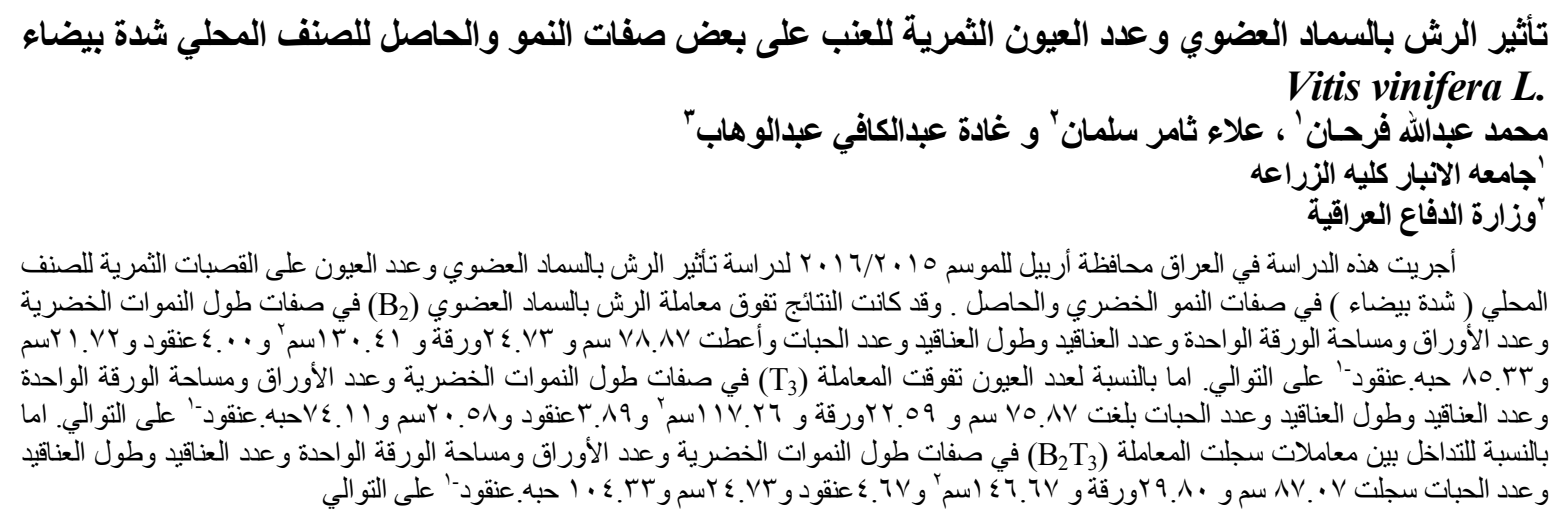

